\title{
A SOCIO-LINGUISTIC APPROACH TO THE DEVELOPMENT OF FOLK PSYCHOLOGY
}

\author{
DAVID OHREEN
}

\begin{abstract}
One of the most interesting issues central to folk psychology is how it develops in humans. Over the past few decades, two distinct theories have emerged known as the Theory-Theory and Simulation Theory. Theory-theory supporters argue that children construct theories to explain behavior, while simulation theorists extol the virtues of empathy_putting yourself in another person's shoes. I argue that each position falls short of an adequate account of how folk psychology develops. Instead, explaining behavior is a matter of acquiring folk psychological concepts within a culture and then learning how to deploy such terms with competence.
\end{abstract}

Keywords: folk psychology; language; child development; simulation; theory-theory.

\section{Introduction}

Over the past fifteen years, two competing theories have emerged to explain the development of folk psychology known respectively as Theory-Theory and Simulation. Specifically, each theory claims to solve the developmental riddle between the ages of three and five years when children begin to understand that other people's beliefs, desires, and thoughts can differ from their own. In short, it is claimed that children begin to develop what is known as a theory of mind, that is, an understanding that they themselves and other people have mental statessometimes very different mental states-that govern their actions. Before this age, children tend to assume everyone sees the world from their own point of view and have the same mental states as themselves. This milestone, say researchers, is crucial because seeing others as having different mental states from oneself is the first step to successfully explain and predict behavior.

The debate between theory-theory and simulation has sparked the interests of both philosophers and psychologists alike, resulting in a deluge of papers, which are often complex and difficult to digest. Although my review of the literature will not be exhaustive, I start by outlining the main tenets of both theories, some related problems, and then propose a radically different approach. Theory-theory and simulation theory probably each play some role in how adults explain behavior, but how it develops, I will argue, is not by any of these methods. The ability to explain other people's behavior using mental states-folk psychology-in my account is culturally developed. Both theories tend to ignore the importance of socially acquired concepts like belief, desire, hope, fear, etc., in determining human action and, perhaps more importantly, how people explain behavior. This, I think is a dangerous error. At some point, cultural learning must take center stage. I will argue that folk psychological concepts 
and how we deploy them to explain behavior are largely, although not exclusively, a cultural phenomenon. In the end, my socio-linguistic approach to folk psychology offers a much more plausible and realistic explanation of the discrepancy found between three- and five-year-old children.

\section{The Theory-Theory}

Theory theorists argue that people draw on a theory of mind to understand behavior and psychological states. Alison Gopnik (1988; 1990; 1992; 1993; 1996a; 1996b), one of the leading proponents of the theory-theory view, has an interesting position regarding how folk psychology develops in children-she says it's constructed. The idea of theoretical construction in children is supported, so Gopnik claims, by development research and also by looking at change in scientific theories. Just as scientists change and revise their theories in light of new evidence, so too children refine their theories of mind as new experiences present themselves. Although she supports the idea that there may be a "rich innate starting point," children are like scientists, modifying and changing their theories of mind as new evidence or situations develop. In short, Gopnik suggests, children are not so much little scientists, as scientists are big children. In this way, children around the age of four begin to appreciate that people really have mental states directed at or "about" the world in some fashion. Children come to have beliefs about the beliefs (also known as metarepresentation) of others and how they fit with reality. Intentionality (aboutness) is theoretically constructed as children grapple with making sense of the people in their lives. There is, however, an obvious problem with the theory-theory view. If there are no grounds for thinking folk psychology is theoretical, then the theory-theory collapses altogether. ${ }^{1}$ Despite the fact this argument alone would be sufficient to refute Gopnik's claims, philosophers and psychologists alike trumpet the developmental literature in support of nomological theory construction, specifically what has become known as the false-belief task. This task has been developed into the primary test in determining whether children have a theory of mind.

In the original false-belief experiment by Wimmer and Perner (1983), to test children's theory of mind, a puppet named Maxi places a piece of chocolate in a box, then goes out to play. While he is out, his mother comes home and moves the chocolate from the box to the cupboard. After the audience, made up of three- and four-year-old children, watches the events unfold in the form of a puppet show, they are questioned as to where Maxi will look for the chocolate when he comes back from playing. Given that the audience has access to information of which Maxi is unaware (namely, that Maxi's mother moved the chocolate from the box to the cupboard), all the children should respond similarly. However, this is not the case. Children over the age of four responded correctly, either through pointing or verbally answering that Maxi should mistakenly look in the box for the chocolate instead of the cupboard. Four-year-olds seem to have grasped the notion that Maxi will have a false belief about where the chocolate is, i.e., in the box instead of the cupboard, since this is where he last placed it. Three-year-olds, on the other hand, have a different response, pointing or answering that Maxi will look for the chocolate in the cupboard, when, in fact, Maxi mistakenly believes that it is in the box. Threeyear-olds do not conceive of the possibility of Maxi having a false belief. ${ }^{2}$

\footnotetext{
1 For objections against the idea that folk psychology is theoretical, see Wilkes 1984; 1986; 1991.

2 For results of other false-belief tasks, see Gopnik and Astington (1988), and Flavell et al. (1983).
} 
How is this apparent discrepancy between three- and four-year-olds to be explained? According to Gopnik, our knowledge of other people is constructed between the ages of three and five years of age. Three-year-olds regard people as being connected, by propositional attitudes, to objects or states of affairs, but fail to understand that the other's belief may be false. The observing child, in other words, understands that Maxi's belief refers to or represents some aspect of current reality but fails to conceive that the content of the belief may depict reality in a misleading way. The three-year-old does not understand that others may have beliefs different from his own and will therefore answer incorrectly that Maxi will look for the chocolate in the cupboard. In short, three-year-olds cannot conceive of the content of Maxi's belief referring to or representing a reality different than their own. This inability to make successful and accurate predictions and explanations pushes the child to develop different theories about the world. Theoretical construction allows children to explain facts about the mind and world that would otherwise be inexplicable, namely, mental-state change and diversity, and the causal relations between the world and our beliefs and desires of it. Four-year-olds, therefore, come to understand that, even though beliefs may refer to or represent reality in some fashion, the content of those beliefs may be false. Maxi will thus search in the wrong place for the chocolate. Without the construction of alternative theories, the three-year-old child consistently fails to predict and explain behavior. According to Gopnik this puts children on a par with scientists. She states:

The evidence of developmental psychology, and indeed the evidence of common observation, suggests that young children have learning capabilities (and we would claim theory formation abilities) far in excess of anything we might imagine in our daily cognitively stodgy experience as adults. Indeed we would say, not that children are little scientists but that scientists are big, and relatively slow, children. The historical progress of science is based on cognitive abilities that are first seen in very young children (Gopnik 1992, 168).

Children, in other words, construct theories of mind as they mature. Children are like good little scientists taking information from the world and adjusting their theories accordingly to fit the data. Over time they construct a theory of mind, to explain how his or her own and other people's beliefs and desires relate to the world. That is, children come to see themselves and others as having minds that hold mental states and thereby are successful at predicting behavior. Moreover, Gopnik thinks that theory formation "goes all the way down" starting right from our grand entrance into this world via the birth canal. She writes, "I do think it is theories all the way down... at birth, infants already draw some inferences about human behavior that go well beyond the direct evidence of their senses" (Gopnik 1996b, 510). An example of such inferences would be an infant's imitation of facial expressions. Infants make abstract inferences from the facial gestures of others about how they might subsequently behave. She also thinks theory-theory is universal. Informal knowledge of human psychology varies little from culture to culture; hence, this suggests that children worldwide develop the same theories of mind at almost exactly the same age. ${ }^{3}$

\footnotetext{
3 Although Gopnik espouses a rather extreme form of theory-theory, Stich and Nichols (1992) offer a different theoretical approach. I will not address specific objections against Stich and Nichols, but suffice to say, that much of what I say against Gopnik can equally be leveled against them.
} 


\section{Problems with Theory-Theory}

Gopnik, however, runs into trouble. If theories of mind are constructed as the child gathers evidence from the culture in which they are raised, then it means that the theories are imbued with cultural baggage. Gopnik cannot explain how children all over the world acquire the same folk psychology at exactly the same age if the theories end up relative to their specific culture. In fact, given that all children are raised in uniquely different households with perhaps uniquely different experiences, there would probably be as many theories of mind as there are children. Moreover, if infants start from scratch slowly building their theory of mind over time, then it seems likely that there would be cultural differences in how behavior is explained theoretically. In short, Gopnik's claim that children construct the same universal folk psychological theories to explain behavior is highly suspect.

There are also deeper problems with the theory-theory. If the development of folk psychology is a sequence from crude to sophisticated theories, then theory-theory should be able to tell us what these in-between theories are like. Gopnik's explanations are suspiciously scant. It's implausible to think a four-month-old infant develops theories to explain why she is latched on to her mother's breast, why she eats such bland food, and why daddy can't change her diapers properly. And the example Gopnik gives is very unhelpful; imitating facial expressions is hardly a form of theoretical inference. I suspect an infant's imitation of mommy's smile is simply an unconscious response to an external stimulus or at most a conscious thought like "There's mommy," but these are nothing remotely like scientific theories or theoretical construction. Gopnik also thinks that three-year-olds cannot appreciate the mental states of other people, but she does not specify what exactly the theory they hold would look like. Theory-theory fails to explain the uniformity of the developmental sequence and cannot give an adequate account of precursor theories (Sterelny 1998). In fact, Gopnik cannot explain how infants glean enough usable information early in life to construct theories in the first place. At life's beginning infants live in a world of intellectual poverty, at least when compared to that of a scientist's. Sleeping, eating, defecating, and spitting up seem to be an infant's primary concerns. It's hard to believe that infants are able to somehow take this information and roll it into a nice little theory about baby sleep habits, potty rituals, or teddy bears. In short, I don't think theory-theory is tenable at all. Without a proper explanation of what baby theories would look like, Gopnik's explanation ends up hollow and inane.

Theory-theorists might complain that I have misrepresented their position. It does seem rather ludicrous to suggest that children, like scientists, hover over experimental equipment constructing psychological explanations. Scientists, unlike children, also have a wealth of knowledge and practical experience, and, more importantly, can express their theories explicitly using sophisticated terminology. Children, in contrast, do none of these things. They do not explicitly talk about theory formation or evaluate theories, nor do they perform experiments in institutional settings or write journal articles. And if you ask a child around four years of age what a belief is, she will look at you in utter bewilderment. Theoretical constructs, theorytheorists might say, do not take place explicitly, but tacitly. In other words, children do construct theories about how mental states are related to the world despite the fact they don't have the vocabulary to say what they are. Gopnik seems to suggest this when she says, "...the kinds of knowledge we attribute to the child on this basis may not always be consciously accessible to the child in exactly the form we describe" (Gopnik 1990, 90). In this sense, much of our understanding of people may be unconscious and inexpressible.

Putting theory formation this way does not strike me as intuitively correct. Let's look at the false-belief task again. As I understand Gopnik, three-year-olds are mistaken about where Maxi 
will look for the chocolate because they have a faulty theory about the mental states of others. They lack the ability to appreciate alternative or contradictory models of reality. Four-yearolds, in contrast, are able to predict where Maxi will look for the chocolate because evidence and relevant information are taken into account to produce a more sound theory. Hence, four-year-olds come to understand that beliefs may refer or represent reality differently from their own, and, most importantly, those beliefs may be false. But if such theory formation is beyond the reach of consciousness, it suggests that when children are using theories to explain behavior they are totally unaware of what they are doing. And this turns out to be very odd. As Guttenplan $(2000,112)$ nicely explains, if psychological theories turn out to be tacit,

... it requires us to say that 'most of us are unaware of what we are doing' when we explain why people act as they do....It seems not just implausible, but deeply mistaken, to say that when we formulate various stories [theories] about what went wrong we are unaware of what we are doing.

It seems ridiculous to say that children are totally unaware of what they are doing when they explain where Maxi will look for the chocolate in the false-belief experiment. Surely children would have to be aware of what they are doing to attempt any explanations in the first place.

\section{Simulation Theory}

Roughly speaking, simulation differs from theory-theory in that behavioral explanation and prediction is not based upon theories or generalizations; rather, the person simply "puts him or herself in the other person's shoes." According to simulation theory, children imagine what they would do in a similar situation had they the same beliefs and desires as another person. In this way, beliefs and desires can be inferred to explain and predict behavior, and also to understand intentionality.

Robert Gordon (1986, 1992a), one of the leading proponents of this theory, argues that the simulator does not project his or her own situation and psychology onto another person but simply makes the necessary imaginative adjustments to narrow the differences between him or herself and the simulatee. To put yourself in another person's shoes really means cognitively "taking up the slack" in regards to differences in upbringing, education, social values, temperament, and epistemic situation. It is through such an adjustment that causal explanations of behavior succeed. So, for example, to explain why Fred ran down the mountain, all you have to do is imagine what the world looks like from his position with a fierce and menacing grizzly charging straight towards you and then attribute these beliefs and desires to Fred as the cause of his behavior. In short, you come to see the world through the other person's eyes and, in a sense, simulate them.

Now in order to get simulation off the ground, we have to assume that people everywhere possess the same fundamental cognitive capacities and propensities for action as we do. In this sense, we use ourselves to determine regularities in behavior, which can then be used for explanation and prediction. For simulation theory, when we try to understand others' behavior, we do not bring it under some law-like generalization but instead try to make sense of the other person. We assume that behavior is intelligible based on our knowledge of the world and our ability to imagine. In short, we imagine having the same mental states as another person and then explain the actions in question. ${ }^{4}$

${ }^{4}$ Goldman (1992) offers a slightly different account of the simulation theory than Gordon. For Gordon, simulation occurs by "putting ourselves in the other person's shoes." By doing so we come to 
How might simulation theory account for the developmental evidence? Let's look at the false-belief experiment. We saw earlier that children over the age of four responded correctly, by pointing or verbally answering, that Maxi should mistakenly look for the chocolate in the box instead of the cupboard. Four-year-olds seem to have grasped the notion that Maxi will have a false belief about where the chocolate is, i.e., in the box instead of the cupboard, since this is where he last placed it. Three-year-olds, on the other hand, answer that Maxi will look for the chocolate in the cupboard, when in fact Maxi mistakenly believes that it is in the box. Threeyear-olds, it is said, do not conceive of the possibility of Maxi having a false belief. Paul Harris (1992) argues that the change in three- and four-year-olds is not a transformation of the child's theory about minds, but a change in the child's imaginative flexibility. Increased imaginative flexibility allows the child to imagine another person holding beliefs about a situation that are contrary to their own beliefs about the same situation. In other words, the three-year-old child lacks the ability to make the necessary mental adjustments in order to put themselves in the other person's shoes. Four-year-olds, in contrast, make allowances for what people are not in a position to know about reality by an increased ability to imagine that their own beliefs and desires are someone else's, hence simulating them and thereby being able to understand belief failures. Three-year-olds do not make such imaginative allowances, construing Maxi's beliefs about where the chocolate is as similar to their own (i.e., the chocolate will be in the cupboard), whereas fouryear-olds, by making the necessary adjustments, are able to pinpoint the relevant ignorance.

\section{Problems with Simulation Theory}

The problem with simulation theory, say critics, is that it masks the real underlying psychological causes of behavior. Putting yourself in another person's shoes is one thing; trying to explain his or her behavior from this perspective is quite another. Objectors argue that simulation theory is instrumentalist; it does not really offer a genuine understanding or explanation of why someone did what they did. All it gives us is a methodology for ascribing and predicting, but no real explanation of the behavior in question. The only way to imbue simulation theory with explanatory power is to bring in theoretical assumptions about human behavior that is motivated by common antecedents in the forms of reactions, desires, and so on. So, for example, even if I put myself in Fred's shoes as he is running down the mountain, it still begs the question of why he is behaving like he is. Simply putting myself in his shoes will not offer any explanatory punch. What I need is some general theory about how people behave when they have specific beliefs and desires that I can map onto the situation. Without such theories there is no way I could predict what Fred will do. Something deeper must account for Fred's actions if simulation is to have any credibility. And this can only come from general theoretical claims that people confronted by grizzlies will be afraid, people desire not to be killed, grizzlies are dangerous, and, when scared, people will either fight or flee. In this way, simulation theory must be imbued with some form of theory-theory. ${ }^{5}$

see the world through their eyes (take on their beliefs and desires) and predict what they would do. In contrast, Goldman argues, we "put ourselves in the other person's situation." That is, instead of taking on another person's mental states, we introspect to see what we would do in that particular situation and then infer that the other person will have similar states. For objections to Goldman's approach, see Gordon (1996).

5 For an explicit formulation of a hybrid theory/simulation theory, see Heal (1996). 
Another problem simulation theory faces is interpretative indeterminacy (Beebe 2001). In order for simulation to work, people must feed into their cognitive machinery the hypothetical mental states of other people. But because people can have an indefinite number of mental states, it's indeterminate which of these are needed for simulation to achieve predictive success. Simulation theory doesn't give us any way of determining which of these indefinite beliefs and desires must be used. Hence, some people may simulate radically different beliefs and desires and come up with radically different explanations or predictions of actions. Theory-theory wouldn't have this problem since everyone will construct the same belief/desire psychology and apply it consistently to specific behaviors.

\section{A Socio-linguistic Approach}

Given the problems with both theory-theory and simulation theory, let me offer a different approach to concept acquisition and folk psychology generally. Children would never come up with folk psychological terms if they were not raised in a culture that values explaining and predicting behavior. Cultures that emphasize mental states will teach their children the necessary folk psychological terms as part of the socialization process. Concept acquisition starts from the social world, which is then internalized. Once internalized, the child can then begin to explain behavior by virtue of mental states.

Right from the start a newborn infant is immersed in a world of language. Children are talked to, talked at, and talked about. Because folk psychology is so ingrained in the English language, parents can't help but talk to their infants about various wants, thoughts, feelings, and so on. Moreover, the child will be audience to hundreds or thousands of conversations imbued with folk psychological terms. As the child grows and learns language, she will gradually come to see herself as being in such states, which can then be applied to others. Folk psychology, in my account, will be largely determined by how important the mind is to that culture. The more important folk psychology is to a culture, the more the child is encouraged to actively participate in its normative folk psychological ways and learn its folk psychological language. In this sense, the concepts of belief and desire are learned in the child's social world and, as the child grows and becomes more linguistically competent, the better he or she will be at applying these terms to themselves then to others to explain what they are doing. I am not sure how strict this learning sequence is; it might be more fluid than I make it out to be. Nor do I want to suggest that learning folk psychological concepts is different from, or comes before, learning how to apply them correctly. For this might mean that a child can understand mental-state terms without being able to apply them. My suspicion is that learning folk psychological concepts goes hand in hand with learning how to apply them to oneself and other people. If correct, linguistic competence of folk psychological terms is the key through which the mysteries of explanation and prediction are unlocked. Janet Astington (1996, 187-188) holds similar views stating:

...linguistic development is fundamental to the acquisition of mental state concepts because without language the child would not learn about these concepts, which are in the speech practices of the culture. In this sense the theory of mind, perhaps even mind itself, is a cultural invention.

On this view, children don't acquire a theory of mind on their own but instead, through participating in the culture, come to share the culture's ways of regarding and talking about mental states. But not all cultures share the same interests in folk psychology or explain 
behavior the same way. Although Western cultures explain and predict behavior using mental terms, some cultures, like the Azande (Evans-Pritchard 1976), place explanatory importance on witches and oracles. Again, in my view, folk psychology is, in part, a cultural phenomenon. Let me sketch, in a very rough way, how culture might influence a child's development of folk psychology in Western society.

In Western societies, we pay a great deal of attention to our own minds and the minds of others. In fact, our culture is replete with mental terms. I am suggesting that our folk psychological concepts are not determined by simulation or theory, but socially. A child's first exposure to folk psychology is not experienced personally through simulation or theory construction, but as part of his or her social world. This idea is taken from the Russian psychologist Lev Vygotsky $(1962,1978)$, who considered the child's social environment crucial for cognitive development. For Vygotsky, learning language for a child is primarily a tool for social communication, first and foremost, which allows the child to communicate what it wants, desires, and needs. It's only later as the child matures that concepts take on an internal mental role. It's no wonder then the process of internalizing social linguistic practices takes the form of egocentric speech. As Astington (1996, 190) explains,

Initially, an adult's speech directs the child's behaviour and then later, the child talks to herself-egocentric speech-directing her own behaviour. Gradually, this egocentric speech ceases to be expressed aloud, becoming inner speech, or verbal thought.

In other words, the child gradually starts to take his or her socialized speech and turn it to him or herself. And it's in the form of egocentric speech that the child gradually learns to apply social terms to his own behavior. Once mastered, the child can then learn to apply it to others. If we extend this idea to folk psychology, the child will first experience folk psychology as a social phenomenon, which is then gradually internalized to explain their own behavior and then extended to other people. Children are exposed to mental-state talk in a variety of mediums such as adult conversations, bedtime stories, and television. Children will first come to understand folk psychology language as a form of social communication, which is then internalized by referring to their own thoughts. Although these initial folk psychological terms may be used to express egoistic wants and needs, once mastered, they can be applied to others as a means of explaining and predicting behavior.

This is by no means a detailed account of how Vygotsky's theory might work, but developmental evidence seems to support my basic idea that social interaction is necessary for understanding false beliefs. Dunn et al. $(1991,1996)$ found that family interaction and discourse were important antecedents to children getting the false-belief task right. Research by Perner et al. (1994) also argue a connection between doing well on the false-belief task and social interaction; finding that children with two or more siblings were twice as likely to pass the falsebelief task. A follow-up study by Jenkins and Astington (1996) looked at the rates of language development between only children and those with one or more siblings. Their findings support the conclusions of Perner et al. that children in large families did better on the false-belief task. What this seems to suggest is that social interaction is important for children in developing linguistic competence of folk psychological terms. As I understand the experiments, increased social intercourse increases linguistic competence, which in turn is reflected in the ability to successfully attribute mental states to others, leading to better results on the false-belief task. These studies indicate that social interaction and language learning skills play a fundamental role in the theory of mind development without the need of theoretical constructs or increase imaginative flexibility. 
Moreover, compared to acquiring other words like proper names, learning the concepts of folk psychology is a curious enterprise. Beliefs and desires are not something we point out to children the same way we point out puppies, colors, boats, or the alphabet. We don't point to mental states and say, "That is a belief" in the same way we point to a frog and say, "That is a frog." Although, we might tell children in an offhanded way, "Mommy is angry" or "Sally believes you are lying," we don't get children to repeat mental-state words the way we get them to repeat, say, animal words. As Wittgenstein (1953) pointed out long ago, we learn words not merely by ostensive definition but in learning how words are used. Folk psychology is similar; children learn the concepts of folk psychology from their environment. The concepts of belief and desire are not taught in any strict ostensible way; they are understood as adults talk about them casually in their everyday conversations. Folk psychology, so to speak, is learned as part of the child's linguistic landscape. The child begins to associated mommy or daddy's talk about beliefs, desires, or hopes with certain actions and emotions; they begin to learn how such words are used. As the child matures and has a firmer grip on language, she might start to refer to their own behavior and thoughts in folk psychological terms. With further competence, the child, by the age of four, will have mastered enough folk psychological terms to begin to attribute them to other people. My point is that explaining and predicting behavior using mental states is really a matter of linguistic practice. Learning to apply words correctly in the proper contexts takes time. Children first learn folk psychological concepts in their social environment, secondly apply these concepts internally to themselves, and then thirdly to others. Therefore, the mistake of a three-year-old on the false-belief task might just be part of the procedure of learning how to apply the concepts of folk psychology correctly. No simulation or theories needed.

Support for my socio-linguistic approach to folk psychology comes sharply into focus when we look at how other cultures explain behavior. It would be na ve to assume that all cultures share the Western view that behavior is caused by mental states. It would also be mistaken to assume that explaining behavior via mental-state attributions is also universal. Evidence suggests that there is more than one way to construe the mind and its manifest actions. For example, Hindu Indians, Chinese, and Saudis, are more likely to attribute situational factors rather than internal mental states as reasons for behavior (Miller 1984). And ethereal causes of behavior are also emphasized more in some cultures than the West. The ancient Greeks believed that one role of the Greek gods was to direct behavior. The Baining of Papua New Guinea (Fajans 1997) also accept the fact that ghosts or bush spirits (aios) sometimes cause people to do strange and "crazy" things. In African Azande culture (Evans-Pritchard 1976) accidents, such as starting a fire, are seen as being caused by witches. And in Samoan culture (Ochs 1988), people are seen as having little control over their emotions and, therefore, are not held responsible for their behavior. All of these examples clearly illustrate that some cultures profile causes of behavior that are radically different than our mind-dominated Western view. The differences in the level of interest in minds and subsequent folk psychological explanations seem to be largely culturally determined.

Unfortunately, much of the literature on folk psychology does not recognize cultural variations in how they explain and predict behavior. Research by Lillard $(1997,1998)$ shows that many cultures do not share the same zest for psychological explanation, and some even consider the mind as unimportant. Lillard presents a smorgasbord of theories of mind from around the world that is interesting and informative. The upshot undercuts any claims of universality. This, however, doesn't mean cultures are completely bereft of folk psychology. Most cultures recognize, to varying degrees, mental states, but how they explain and predict behavior may not depend on a belief/desire psychology. Western societies (or perhaps it's merely Western 
philosophers and psychologists) place considerable importance on mental states (beliefs and desires) as the cause of behavior. For other cultures, however, beliefs and desires are not a pressing topic of conversation, and, hence, they come to explain behavior in very different ways.

\section{Conclusion}

I have proposed an account of folk psychology that is derived from one's culture, not theory-theory or simulation theory. Folk psychology is really just a matter of learning concepts and then learning how to apply them correctly. Now I don't want to rule out theory-theory or simulation theory completely. I think both theories have a role to play in adult explanations and predictions of behavior. However, where some philosophers and psychologists have gone wrong is in assuming that folk psychology is derived from either personal experience via empathy or theory construction. Mental-state terms must be learned in one's social environment first before they can be used in explicit folk psychological ways to explain and predict behavior.

\section{References}

Astington, J. What is Theoretical about the Child's Theory of Mind?: A Vygotskain View of its Development. In P. Carruthers, P. K. Smith (Eds.). Theories of Theories of Mind. Cambridge: Cambridge University Press, 1996.

Beebe, J. Interpretation and Epistemic Evaluation in Goldman's Descriptive Epistemology. Philosophy of the Social Sciences 31, 163-86, 2001.

Dunn, J., Brown, J., Slomkowski, C., Tesla, C., Youngblade, L. Young Children's Understanding of Other People's Feelings and Beliefs: Individual Differences and Their Antecedents. Child Development 62, 1352-66, 1991.

Dunn, J. Family Conversations and the Development of Social Understanding. In B. Bernstein, J. Brannen (Eds.). Children, Research and Policy: Essay for Barbara Tizard. Washington: Taylor and Fancis, 81-95, 1996.

Evans-Pritchard, E. Witchcraft, Oracles, and Magic Among the Azande. Oxford: Clarendon Press, 1976.

Fajans, J. They Make Themselves: Work and Play Among the Baining of Papua New Guinea. Chicago: The University of Chicago Press, 1997.

Flavell, J., Flavell, M., Green, M. Development of the Appearance-Reality Distinction. Cognitive Psychology 15, 95-120, 1983.

Gopnik, A., Astington, J. Children's Understanding of Representational Change, and Its Relation to the Understanding of False Belief and the Appearance-Reality Distinction. Child Development 59, 26-37, 1988.

Gopnik, A. Developing the Idea of Intentionality: Children's Theories of Mind. Canadian Journal of Philosophy 20, 89-114, 1990.

Gopnik, A., Wellman, H. Why the Child's Theory of Mind Really is a Theory. Mind and Language 7, 145-71, 1992

Gopnik, A. How We Know Our Minds: The Illusion of First-Person Knowledge of Intentionality. Behavioral and Brain Sciences 16, 1-14, 1993.

Gopnik, A. Theories and Modules: Creation Myths, Developmental Realities, and Neurath's Boat. In P. Carruthers, P. K. Smith (Eds.). Theories of Theories of Mind. Cambridge: Cambridge University Press, 1996a.

Gopnik, A. The Scientist as Child. Philosophy of Science 63, 485-514, $1996 \mathrm{~b}$.

Goldman, A. In Defense of the Simulation Theory. Mind and Language 7, 104-19, 1992.

Gordon, R. Folk Psychology as Simulation. Mind and Language 1, 158-71, 1986. 
Gordon, R. The Simulation Theory: Objections and Misconceptions. Mind and Language 7, 11-34, 1992a.

Gordon, R. Radical Simulation. In P. Carruthers, P. K. Smith (Eds.). Theories of Theories of Mind. Cambridge: Cambridge University Press, 1996.

Guttenplan, S. Mind's Landscape: An Introduction to the Philosophy of Mind. Oxford: Blackwell Publishers, 2000.

Heal, J. Simulation, Theory and Content. In P. Carruthers, P. K. Smith (Eds.). Theories of Theories of Mind. Cambridge: Cambridge University Press, 1996.

Jenkins, J. M., Astington, J. W. Cognitive Factors and Family Structure Associated with Theory of Mind Development in Young Children. Developmental Psychology 32, 70-78, 1996.

Lillard, A. Other Folks' Theories of Mind and Behavior. Psychological Science 8, 268-74, 1997.

Lillard, A. Ethnopsychologies: Cultural Variations in Theories of Mind. Psychological Bulletin 123, 3-32, 1998.

Miller, J. Culture and the Development of Everyday Social Explanation. Journal of Personality and Social Psychology 46, 961-78, 1984.

Ochs, E. Cultural and Language Development: Language Acquisition and Language Socialization in a Samoan Village. Cambridge: University of Cambridge Press, 1988.

Perner, J., Ruffman, T., Leekam, S. Theory of Mind is Contagious: You Catch It from Your Sibs. Child Development 65, 1228-38, 1994.

Sterelny, K. Intentional Agency and the Metarepresenation Hypothesis. Mind and Language 13, 11-28, 1998.

Stich, S., Nichols, S. Folk Psychology: Simulation or Tacit Theory? Mind and Language 7, 35-71, 1992.

Vygotsky, L. Thought and Language. Cambridge, Mass.: MIT Press, 1962.

Vygotsky, L. Mind on Society. Cambridge, Mass.: Harvard University Press, 1978.

Wilkes, K. Pragmatics in Science and Theory in Common Sense. Inquiry 27, 339-61, 1984.

Wilkes, K. Nemo Psychologus Nisi Physiologus. Inquiry 29, 169-85, 1986.

Wilkes, K. The Relationship Between Scientific Psychology and Common-Sense Psychology. Synthese 89, 15-39, 1991.

Wimmer, H., Perner, J. Beliefs about Beliefs: Representation and Constraining Function of Wrong Beliefs in Young Children's Understanding of Deception. Cognition 13, 103-28, 1983.

Wittgenstein, L. Philosophical Investigations. Trans. G.E.M. Anscombe. New York: MacMillan Publishing Co., Inc., 1953.

Faculty of Management

University of Lethbridge (Calgary Campus)

N 104, $1301-16^{\text {th }}$ Ave. NW

Calgary, Alberta

Canada

Tel.: (403) 774-4979

E-mail: david.ohreen@uleth.ca 